\title{
Exercise Capacity Impairment Can Predict Postoperative Pulmonary Complications after Liver Transplantation
}

\author{
Clarissa Bentes de Araújo Magalhães ${ }^{a}$ Ingrid Correia Nogueira ${ }^{a}$ \\ Liegina Silveira Marinho $^{a}$ Elizabeth F. Daher ${ }^{a}$ José Huygens P. Garciab, c \\ Cyntia F.G. Vianac Pedro Felipe Carvalhedo de Bruin ${ }^{a}$ \\ Eanes Delgado Barros Pereira ${ }^{a}$ \\ ${ }^{a}$ Department of Medicine, ${ }^{\mathrm{b}}$ Department of Surgery, and ${ }^{\mathrm{C}}$ Liver Transplantation Center, Walter Cantidio \\ University Hospital (HUWC), Federal University of Ceará, Fortaleza, Brazil
}

\section{Keywords}

6-minute walk test - 6-minute step test · Lung function ·

Postoperative complications · Liver transplantation

\begin{abstract}
Background: Postoperative respiratory complications (PRCs) are common after liver transplantation (LT) and contribute significantly to the related morbidity and mortality. Objective: The aim of this paper was to determine the incidence of PRCs after LT and the value of simple exercise capacity measures as independent predictors of PRCs. Methods: We conducted a prospective cohort study of consecutive adults submitted to LT at a University Hospital in Fortaleza Brazil from March 2013 to March 2015. At baseline, exercise capacity was assessed with the 6-minute walk test (6MWT) and the 6-minute step test (6MST), lung function was tested by spirometry, and respiratory muscle strength was measured by maximal respiratory pressure. Additional relevant pre-and intraoperative data were collected through interview and chart review, and their association with the incidence of PRCs was evaluated. Results: The study included 100 subjects, $44 \%$ of whom presented at least 1 of the PRCs. In the univariate analysis, poor 6MST and 6MWT results
\end{abstract}

\section{KARGER}

(C) 2017 S. Karger AG, Basel

E-Mail karger@karger.com

www.karger.com/res and a longer preoperative cold ischemia time were associated with PRCs. The logistic regression analysis showed that PRCs were less likely to occur when preoperative walking distances were longer: the odds ratio $(95 \% \mathrm{Cl})$ was reduced to 0.589 (0.357-0.971) for each $50 \mathrm{~m}$ walked $(p=0.03)$. Likewise, PRCs were more likely to occur in patients with longer preoperative cold ischemia times: the odds ratio $(95 \% \mathrm{Cl})$ increased to $1.008(1.002-1.015)$ for each minute $(p=0.01)$. Conclusion: The incidence of PRCs is high in LT patients. A prolonged cold ischemia time and preoperative 6MWT results were independent predictors of PRCs in this patient population.

(c) 2017 S. Karger AG, Basel

\section{Introduction}

Liver transplantation (LT) is currently an important treatment for chronic end-stage liver disease (ESLD). Postoperative respiratory complications (PRCs) contribute to LT-related morbidity and mortality, both in the acute and long-term postoperative stage [1]. Major PRCs include pneumonia, moderate/severe pleural effusion, acute respiratory failure (ARF), and atelectasis [1-5].

Eanes Delgado Barros Pereira, $\mathrm{PhD}$

Department of Medicine, Federal University of Ceará

Rua Prof. Costa Mendes

Fortaleza, CE 60140000 (Brazil)

E-Mail eanes@fortalnet.com.br 
Routine preoperative evaluation of LT candidates is directed at specific organ systems and generally includes pulmonary function tests. However, as ESLD patients usually suffer from fatigue, muscle wasting, malnutrition, and weakness, it is difficult to obtain an objective assessment of overall fitness. In a study on 47 LT candidates, Mancuzo et al. [6] found an independent association between aerobic capacity (peak $\mathrm{VO}_{2}$ ) and time of hospitalization, matching the findings of Bernal et al. [7].

The 6-minute walk test (6MWT) and the 6-minute step test (6MST) are simple low-cost tests to measure exercise capacity, but their usefulness in the assessment of ESLD patients has not been sufficiently evaluated. It has been previously reported that patients with cirrhosis have significantly poorer $6 \mathrm{MWT}$ results than individuals with stable chronic viral hepatitis and healthy volunteers [8]. In a study of patients on the waiting list for LT, a 6MWT result of $<250 \mathrm{~m}$ was a risk factor for mortality before LT [9]. The 6MST has been used to assess exercise capacity in patients with chronic obstructive lung disease and interstitial lung disease, but, to the best of our knowledge, has not been previously evaluated in ESLD subjects [10, 11 .

Previously, Paisani et al. [12] reported that the 6MWT is not a useful tool to identify subjects at an increased risk of developing PRC following upper abdominal surgery. However, there is considerable evidence suggesting that patients with poor exercise test results are at an increased risk for PRCs after major surgery [13-15], probably due to the ability of exercise testing to determine the subject's physiological ability to cope with the demands placed on the cardiorespiratory system following the surgical procedure [16]. A major feature of $6 \mathrm{MWT}$ is the identification of oxyhemoglobin desaturation associated with pulmonary disease, which may not be apparent when the subject is assessed in the resting state. Oxygen saturation deficit may be part of the pathophysiologic basis of PRCs [1].

In order to test the original hypothesis that the 6MST and 6MWT, 2 simple measures of functional exercise capacity, could be independent predictive factors for PRCs after LT, we carried out a prospective study in a cohort of ESLD patients.

\section{Patients and Methods}

This was a prospective study of a cohort of adults submitted to orthotopic LT at a University Hospital in Brazil between March 2013 and March 2015. At first, 110 patients were included, but 10 patients declined to perform the tests or had neurological (hepatic encephalopathy), vascular, or musculoskeletal conditions limiting their ability to walk and were therefore excluded. All subjects listed for LT, with priority for graft allocation, who attended the outpatient LT clinic, were submitted to a preoperative evaluation, including clinical history, physical examination, spirometry, measurement of respiratory muscle strength, $6 \mathrm{MWT}$, and $6 \mathrm{MST}$. As the tests were performed concomitantly, on average 7 days before surgery, they were indeed very up-to-date. Cases with ascites leading to significant functional capacity impairment were routinely drained, and tests were carried out afterwards. After LT, the patients were transferred to an intensive care unit (ICU). Ventilatory strategy included a tidal volume of $6 \mathrm{~mL} / \mathrm{kg}$ of the ideal body weight. As mechanical ventilation with high positive end-expiratory pressure has been reported to impair liver outflow [17], we started with $5 \mathrm{~cm} \mathrm{H}_{2} \mathrm{O}$ and adjusted from 5 to $10 \mathrm{~cm} \mathrm{H}_{2} \mathrm{O}$ according to patient conditions. All patients were followed and received standard respiratory therapy sessions daily until hospital discharge. The length of stay was counted until discharge from hospital or death in the postoperative period. The study protocol was approved by the institutional research ethics committee (filed under entry \#052.07.12), and all participants gave their informed written consent.

\section{Primary Outcome}

The primary outcome was the development of 1 or more of the following major PRCs [18-20].

Pneumonia. Presence of new pulmonary infiltration on a chest $\mathrm{X}$-ray associated with at least 2 of the following signs: purulent tracheobronchial secretion, elevation of body temperature $\left(>38.0^{\circ} \mathrm{C}\right)$, and increase of leukocytes in circulation $(>11,000 / \mu \mathrm{L})$.

Atelectasis. Evidence of pulmonary atelectasis on a chest X-ray with lung opacification and a shift of the mediastinum, hilum, or hemidiaphragm towards the affected area with compensatory overinflation in the adjacent nonatelectatic lung and requiring chest physiotherapy and/or bronchoscopy.

Acute Respiratory Failure. Patients presenting $\mathrm{PaO}_{2} / \mathrm{FiO}_{2}<300$ $\mathrm{mm} \mathrm{Hg}$ requiring invasive or noninvasive mechanical ventilator support for more than $48 \mathrm{~h}$, or reintubation.

\section{Data Collection}

Preoperative information was collected covering demographic data, history of health conditions (systemic arterial hypertension, diabetes mellitus, heart disease, liver disease, or pulmonary disease), the Child-Pugh score, and the MELD (model for end-stage liver disease) score. The intraoperative measurements included the volume (units) of blood components transfused, warm ischemia time, cold ischemia time (CIT), and the duration of surgery. Following LT, all patients were monitored until discharge, and PRCs were recorded.

Respiratory Function and Respiratory Muscle Strength

Spirometry was conducted using an electronic spirometer Vmax (Palm Springs, CA, USA) in accordance with the guidelines of the American Thoracic Society/European Respiratory Society (ATS/ERS) [21]. The following parameters were analyzed: forced expiratory volume in the first second (FEV1), forced vital capacity, maximal inspiratory pressure, and maximal expiratory pressure at the mouth [22]. 


\section{Exercise Capacity}

Exercise capacity was evaluated with 2 standardized tests, $6 \mathrm{MWT}$ and 6MST, performed under the direct supervision of 1 of the investigators. 6MWT measures how far a patient can walk on a flat surface within $6 \mathrm{~min}$ [23]. The test was completed in an enclosed corridor on a flat course $30 \mathrm{~m}$ in length. The subjects were asked to walk as fast as possible from one end of the corridor to the other, as many times as possible within the established time. The distance the patients walked during the 6-min period was registered.

$6 \mathrm{MST}$ is a self-paced test using a step $20 \mathrm{~cm}$ high with a nonslip rubber surface. The subjects were instructed to climb the step as many times as possible during 6 minutes. The more steps completed, the higher the exercise capacity [24].

\section{Statistical Analysis}

The descriptive analysis, with determination of frequencies and the Shapiro-Wilk W test with distribution plots were used to verify the normality of the distribution. Data that did not meet the assumption of normality were expressed as median values and percentiles, and the groups were compared with the Mann-Whitney $U$ test. Normally distributed data were analyzed with the Student $t$ test. For categorical variables, the Pearson $\chi^{2}$ test or Fisher exact test was used, as appropriate. The significance of the risk factors for PRCs was determined by univariate analysis. The variables with a $p$ value $<0.05$ at the univariate analysis were used as independent variables in a logistic regression analysis in which the dependent variable was PRCs. A backward stepwise elimination algorithm was used ( $p=0.05$ ) for the predictors remaining in the final model. All analyses were performed with the software SPSS v. 17.0 (SPSS Inc., Chicago, IL, USA).

\section{Results}

Of the 100 patients enrolled in the study, $98 \%$ received grafts from deceased donors, and $2 \%$ received domino grafts. All patients were submitted to piggyback anastomosis. The cohort was predominantly male (65\%). The median age was 54.5 years (interquartile range [IQ]: 43.261). Viral hepatitis was the most common cause of chronic hepatic failure leading to LT (69\%), but 25 patients presented viral hepatitis and concomitant alcoholic liver disease. The mean $6 \mathrm{MWT}$ and $6 \mathrm{MST}$ values were $348 \pm$ $74.34 \mathrm{~m}$ and $70 \pm 21.8$ steps, respectively (Table 1). The ICU stay lasted from 1 to 32 days (median 2 days), and the total hospital stay from 4 to 45 days (median 10 days). Eighty-four patients were extubated within $24 \mathrm{~h}$, and bronchial toilet was always performed before extubation. In the remaining 16 patients, the median intubation time was 6 days (IQ: 2.5-10.5) and the main reason was pulmonary infection (87\%). Forty-two patients needed blood transfusion, and the median volume was 5 units (IQ: 3-10). Antibiotic prophylaxis was routinely performed with aminopenicillin plus beta-lactamase inhibitor and co-trimoxazole.
Table 1. Preoperative characteristics of liver transplant recipients $(N=100)$

Gender Male $\quad 65$

Age, years

Cause of liver disease Viral liver disease $\quad 69$ Cryptogenic cirrhotic 11 Autoimmune hepatitis 6 Primary sclerosing cholangitis $\quad 1$ HCC

Alcohol Budd-Chiari syndrome MELD

Child-Pugh B and C classification

Pack years of smoking

Hepatopulmonary syndrome

Ascites, \%

Respiratory symptoms

Sputum production

Chronic cough

Dyspnea

Wheezing

Pulmonary disease

Controlled asthma

Bronchiectasis

Interstitial lung disease

COPD

Hemoglobin level

Comorbidities

Arterial hypertension

Heart disease

Diabetes mellitus

$\mathrm{FEV}_{1} \%$

FVC\%

FEV1\%/FVC

MIP, $\mathrm{cm} \mathrm{H}_{2} \mathrm{O}$

MEP, $\mathrm{cm} \mathrm{H}_{2} \mathrm{O}$

6MWT, m

6MST, steps

54.5 [43.2 to 61$]$

69

6
6

1

20 [20 to 22]

80

9.5 [2.75 to 23]

2

58

52

15

33

37

5

29

10

9

4

6

$11.6 \pm 2.2$

39

20

7

30

89 [77 to 99.5]

89.7 [78 to 99.5 ]

82 [77.6 to 86 ]

$-66 \pm 23.8$

$79 \pm 26.6$

$348 \pm 74.3$

$70 \pm 21.8$

Values are presented as numbers, median [interquartile range], or mean \pm standard deviation unless otherwise stated. MELD, model for end-stage liver disease; COPD, chronic obstructive pulmonary disease; FEV1, forced expiratory volume at the first second; FVC, forced vital capacity; 6MWT, 6-minute walk test; 6MST, 6-minute step test; MIP, maximal inspiratory pressure; MEP, maximal expiratory pressure; HCC, hepatocellular carcinoma.

Among the 100 liver transplant recipients, 44 were diagnosed as having at least 1 PRC (Table 2). The most frequent complication was pneumonia, which occurred in the first week. Identification of organisms was possible among 24 patients: Gram-negative bacilli (15), gram-pos-

Magalhães/Nogueira/Marinho/Daher/ Garcia/Viana/de Bruin/Pereira 
itive bacilli (6), and fungi (3). The 30 -day postoperative mortality was $20 \%$, with sepsis as the main cause. Mortality was higher in patients with PRCs versus without PRCs ( 41 vs. $3.5 \%, p=0.001$ ). The ICU and hospital stay were longer among patients with pneumonia versus non pneumonia (6.3 vs. 2.6 days, $p=0.01$, and 18 vs. 10.2 days, $p=$ 0.01 , respectively).

Preoperative risk factors for PRCs are shown in Table 3. There were no significant differences in age, gender, MELD score, Child-Pugh score, international normalized ratio, presence of comorbidities, restrictive syndrome, spirometry, maximal inspiratory pressure, or maximal expiratory pressure between patients who developed PRCs and those who did not. However, the groups differed significantly regarding exercise capacity. Thus, the $6 \mathrm{MWT}$ and $6 \mathrm{MST}$ median values were $314 \mathrm{~m}$ and 60 steps for patients with PRCs versus $371 \mathrm{~m}$ ( $p=$ $0.001)$ and 75.5 steps $(p=0.001)$ for patients without PRCs. In addition, preoperative CIT was longer for patients who developed PRCs. To determine whether $6 \mathrm{MWT}$ and $6 \mathrm{MST}$ were independent predictors of PRC following LT, we performed a multivariate analysis. All significant factors in the univariate analysis were submitted to logistic regression. In the multivariate analysis, higher 6MWT values were associated with a reduced likelihood of experiencing PRCs: the odds ratio (95\% CI) was reduced to $0.589(0.357-0.971)$ for each $50 \mathrm{~m}$ walked ( $p=0.03)$. Likewise, CIT was associated with a greater likelihood of experiencing PRCs: the odds ratio (95\% CI) increased to $1.008(1.002-1.015)$ for each minute $(p=$ 0.04) (Table 4).

\section{Discussion}

This prospective study provides novel evidence that the 6MWT, a simple and low-cost measure of functional exercise capacity, is a predictor of PRCs in patients submitted to LT. We also found that a longer CIT is associated with the incidence of PRCs after LT.

The frequency and distribution of PRCs in our study are in accordance with previously published data [1-5]. The incidence of pneumonia was within previously reported ranges [1-4]. As recently demonstrated by Levesque et al. [5], pneumonia is a major factor of morbidity and mortality after LT [5].

Among patients awaiting LT, ascites and hepatic hydrothorax may, by compression, lead to airway closure and lung reduction $[25,26]$. Following orthotopic LT, atelectasis associated with diaphragmatic dysfunction sec-

Exercise Capacity and Liver

Transplantation
Table 2. Type of PRCs developed by liver transplant recipients

\begin{tabular}{lc}
\hline Subjects having at least 1 PRC & $44(44)$ \\
Only pneumonia & $12(27.2)$ \\
Only atelectasis & $3(6.8)$ \\
Only ARF & $9(20.4)$ \\
Only pneumonia plus ARF & $11(25)$ \\
Only pneumonia plus atelectasis & $3(6.8)$ \\
Only atelectasis plus ARF & $2(4.5)$ \\
Atelectasis plus pneumonia plus ARF & $4(9)$ \\
\hline
\end{tabular}

Values are presented as $n(\%) . \mathrm{PRC}(\mathrm{s})$, postoperative respiratory complication(s); ARF, acute respiratory failure.

ondary to phrenic nerve injury is known to predispose patients to PRCs [27].

Patients submitted to LT are particularly prone to postoperative ARF and lung injury [1-4]. In our cohort, ARF patients had a significantly longer CIT than nonARF patients ( 349 vs. $296 \mathrm{~min}, p=0.03$ ). A prolonged CIT enhances inflammatory response by the activation of nuclear factor-kappa B. A poorly controlled systemic inflammatory response can damage the alveolar-capillary barrier after reperfusion, leading to extravascular fluid accumulation. This type of pulmonary injury is one of the hallmarks of ARF $[1,28,29]$.

The overall postoperative mortality rate was $20 \%$; previous studies showed a distribution from $10 \%$ to $20 \%$ [ 30 , 31]. As expected, the mortality rate was much higher in patients with PRCs than in those without PRCs.

In our series, we demonstrated that for every $50-\mathrm{m}$ increase in the 6MWT, the risk of PRCs after LT decreased. In a study by Carey et al. [9], higher 6MWT results were associated with reduced mortality in LT candidates (the hazard ratio was reduced to 0.58 for each $100 \mathrm{~m}$ walked). Both studies showed that higher 6MWT values reduced adverse events after LT.

Step tests are widely employed to measure exercise capacity, and their use in the assessment of patients with chronic respiratory conditions is well established [32]. However, it has never been used in patients with ESLD. In the univariate analysis of our sample, $6 \mathrm{MST}$ was associated with PRCs, but this was not confirmed in the multivariate analysis, possibly because of the strong correlation (collinearity) between 6MST and 6MWT $(r=0.70$, $p=0.001$ ). Previously, Pichon et al. [33] observed that the number of steps during the $6 \mathrm{MST}$ was significantly correlated with the $6 \mathrm{MWD}$ in patients with chronic obstructive pulmonary disease $(r=0.72 ; p<0.0001)$.

Respiration 2017;94:272-278 275 
Table 3. Risk factors for development of PRCs after liver transplantation

\begin{tabular}{|c|c|c|c|c|}
\hline Risk factors & $\begin{array}{l}\text { PRCs } \\
(n=44)\end{array}$ & $\begin{array}{l}\text { Non-PRCs } \\
(n=56)\end{array}$ & $\begin{array}{l}\text { Unadjusted OR } \\
(95 \% \mathrm{CI})\end{array}$ & $p$ \\
\hline \multicolumn{5}{|l|}{ Gender } \\
\hline Male & 60 & 69 & $1.49(0.65$ to 3.49$)$ & $0.34^{*}$ \\
\hline Age, years & 54 [42 to 59$]$ & $56[45.5$ to 61.5$]$ & $1.01(0.97$ to 1.04$)$ & $0.4^{\dagger}$ \\
\hline \multicolumn{5}{|l|}{ Child-Pugh } \\
\hline $\mathrm{A}$ & 13.9 & 21.8 & & \\
\hline$B$ and $C$ & 81.8 & 78.1 & $1.72(0.58$ to 5.05$)$ & $0.32^{*}$ \\
\hline Cryptogenic cirrhosis & 15.9 & 7.1 & $2.30(0.60$ to 8.60$)$ & 0.19 \\
\hline Previous lung disease & 36.6 & 23 & $2.17(0.90$ to 5.24$)$ & $0.05^{*}$ \\
\hline Respiratory symptoms & 56.8 & 48.2 & $1.52(0.69$ to 3.37$)$ & $0.29^{*}$ \\
\hline Restrictive syndrome & 25 & 16 & $2.84(0.66$ to 12.2$)$ & 0.15 \\
\hline Comorbidities & 34 & 42.8 & $0.76(0.34$ to 1.72$)$ & $0.52^{*}$ \\
\hline Ascites & 65.9 & 51 & $0.51(0.23$ to 1.17 & $0.11^{*}$ \\
\hline Ex-smoker & 46.6 & 54.5 & $0.72(0.33$ to 1.60$)$ & $0.43^{*}$ \\
\hline Alcohol abuse & 71 & 80 & $0.61(0.24$ to 1.54$)$ & $0.29 *$ \\
\hline Blood transfusion volume & $0[0$ to 3$]$ & $2[0$ to 6$]$ & $1.07(0.99$ to 1.15$)$ & $0.07^{\dagger}$ \\
\hline MELD & $20[20$ to 23$]$ & $20[18$ to 22$]$ & $1.03(0.94$ to 1.13$)$ & $0.5^{\dagger}$ \\
\hline INR & $1.5[1.2$ to 1.5$]$ & $1.4[1.1$ to 1.7$]$ & $1.56(0.84$ to 2.87$)$ & $0.15^{\dagger}$ \\
\hline $\mathrm{MIP}, \mathrm{cm} \mathrm{H}_{2} \mathrm{O}$ & $-60[-78$ to -44$]$ & $-73[-86$ to -47$]$ & $1.01(0.99$ to 1.02$)$ & $0.21^{\dagger}$ \\
\hline $\mathrm{MEP}, \mathrm{cm} \mathrm{H}_{2} \mathrm{O}$ & $75[58$ to 101$]$ & $78[62$ to 102$]$ & $0.99(0.98$ to 1.01$)$ & $0.78^{\dagger}$ \\
\hline FEV1\% pred & $83.5[61.2$ to 94.7$]$ & $92[78$ to 100$]$ & $0.98(0.96$ to 1.00$)$ & $0.06^{\dagger}$ \\
\hline FVC\% pred & $87.5[76.3$ to 98.5$]$ & $90.8[80.3$ to 100$]$ & $0.99(0.97$ to 1.00$)$ & $0.46^{\dagger}$ \\
\hline $6 \mathrm{MWT}, \mathrm{m}$ & $314[279$ to 363$]$ & $371[333$ to 414$]$ & $0.98(0.97$ to 0.99$)$ & $0.001^{\dagger}$ \\
\hline $6 \mathrm{MST}$, steps & $60[41.5$ to 74.5$]$ & $75.5[65$ to 87$]$ & $0.95(0.93$ to 0.98$)$ & $0.001^{\dagger}$ \\
\hline Cold ischemia time, $\min$ & $350[264$ to 384$]$ & $290[240$ to 335$]$ & $1.06(1.01$ to 1.02$)$ & $0.01^{\dagger}$ \\
\hline Warm ischemia time, $\min$ & $30[26$ to 37$]$ & $32[29$ to 36$]$ & $0.99(0.93$ to 1.05$)$ & $0.60^{\dagger}$ \\
\hline Duration of surgery, min & 375 [335 to 417$]$ & $350[305$ to 400$]$ & $1.00(1.00$ to 1.01$)$ & $0.09^{\dagger}$ \\
\hline Duration of anesthesia, min & $420[390$ to 450$]$ & $410[360$ to 465$]$ & $1.00(0.99$ to 1.01$)$ & $0.20^{\dagger}$ \\
\hline Tidal volume, $\mathrm{mL}$ & $341[287$ to 371$]$ & $352[314$ to 396$]$ & $0.99(0.98$ to 1.00$)$ & $0.06^{\dagger}$ \\
\hline \multicolumn{5}{|l|}{ ASA classification } \\
\hline II and III & 20 & 16.3 & & \\
\hline IV & 80 & 83.3 & 0.78 (0.28 to 2.17$)$ & $0.63^{*}$ \\
\hline \multicolumn{5}{|l|}{ Donor } \\
\hline Male & 65 & 69 & $0.27(0.65$ to 1.18$)$ & $0.08^{*}$ \\
\hline Age, years & 35 [24 to 49.5$]$ & 42 [25 to 57$]$ & $0.98(0.96$ to 1.01$)$ & $0.28^{\dagger}$ \\
\hline DRI & 1.31 [1.13 to 1.52$]$ & 1.31 [ 1.13 to 1.62$]$ & $0.62(0.16$ to 2.31$)$ & $0.47^{\dagger}$ \\
\hline
\end{tabular}

Values are presented as percentages or median [interquartile range] unless otherwise stated. The tidal volume was based on the ideal body weight. PRCs, postoperative respiratory complications; MELD, model for end-stage liver disease; INR, international normalized ratio; MIP, maximal inspiratory pressure; MEP, maximal expiratory pressure; FEV1, forced expiratory volume in the first second; FVC, forced vital capacity; 6MWT, 6-minute walk test; 6MST, 6-minute step test; ASA, American Society of Anesthesiologists; DRI, donor risk index. ${ }^{*} \chi^{2}$ test; ${ }^{\dagger}$ Mann-Whitney U test.

Table 4. Logistic regression analysis to evaluate the risk factors associated with postoperative respiratory complications after liver transplantation

\begin{tabular}{llll}
\hline Predictor & Adjusted OR & 95\% CI & $p$ \\
\hline 6-minute walk test, per 50 m & 0.589 & $0.357-0.971$ & 0.03 \\
Cold ischemia time, min & 1.008 & $1.002-1.015$ & 0.01 \\
\hline
\end{tabular}

Patients with ESLD may display disorganized muscular, pulmonary, and cardiovascular components of exercise capacity due to impairment in carbohydrate homeostasis and a resting hyperdynamic cardiovascular state [34-36]. Recent studies showed that they develop impairment of exercise capacity and fitness $[37,38]$. Also reduced peak $\mathrm{VO}_{2}$ can help identify patients at risk for mor- 
bidity and mortality after LT $[7,39,40]$. In our study, a poor exercise testing (6MWT) results were indeed predictive of PRCs after LT. A possible explanation for the association of poor exercise capacity and PRCs is the ability of this test to determine patients' physiological capacity to cope with the demands placed on the cardiorespiratory system following major surgery [15].

Unlike most organ-specific evaluations of LT candidates, 6MWT and 6MST provide an objective measure of global physical function. Among the advantages of 6MWT and 6MST over other techniques (such as cardiopulmonary exercise testing for the assessment of LT candidates) are safety, simplicity, and low cost. Although they are submaximal tests able to reflect the functional capacity of the patients, they cannot be used interchangeably [41]. The 6 MWT is more widely used and better validated than the $6 \mathrm{MST}[42,43]$.

In our sample, there was a significant correlation between 6MWT and FEV $1(r=0.33 ; p=0.001)$. Since exercise capacity tests provide an assessment of pulmonary function, in conjunction with cardiovascular and skeletal muscle functions, this correlation is not unexpected and underscores the potential usefulness of these tests for the identification of patients at risk for PCRs. This reinforces the hypothesis that these patients could benefit from physical training (aerobic exercise and weight training) in order to improve exercise capacity before LT as well as in the planning of more individualized and effective rehabilitation programs after surgery.

Although there was a trend, both $\mathrm{FEV}_{1}$ and previous pulmonary disease did not correlate with PRC. The possible explanation could be that patients presented, on average, normal spirometric values and a low frequency of lung disease.

This study has several limitations. Initially, there is no final consensus about the definition of PRCs. For this study, we used only well-defined PRCs with recognized clinical relevance. Although pleural effusion is a common postoperative complication [1-5], it is known that many patients with pre-LT ascites and hepatic hydrothorax continue to accumulate fluid for some time after LT, which complicates its analysis as a relevant outcome. It should be emphasized that our results may be comparable only to studies that used similar definitions of PRCs. Another limitation is the lack of a direct comparison between $6 \mathrm{MWT} / 6 \mathrm{MST}$ and cardiopulmonary exercise testing, which is regarded as the gold standard for the determination of exercise capacity and cardiorespiratory reserve. Finally, as our patients came from a single referral center, it is possible that ESLD subjects from

Exercise Capacity and Liver

Transplantation other LT centers might have somewhat different patient profiles.

In conclusion, the present study confirms that PRCs are common after LT. Prolonged CIT is associated with a higher frequency of PRCs after LT. Lower 6MWT values can identify LT candidates with increased risk for PRCs. Patients that experienced less PRCs presented a reduced risk of mortality. Future research focusing on the validation of the 6MWT in preoperative risk stratification for PRC and mortality after LT, evaluation of other variables $\left(\mathrm{O}_{2}\right.$ pulse, $\mathrm{VO}_{2} \mathrm{max} /$ peak), independently or in combination with the 6MWT, to increase predictive power, as well as new management strategies (physical training) to improve preoperative $6 \mathrm{MWT}$ results and to reduce the risk of PRC is needed.

\section{Acknowledgement} CNPQ.

This study was supported by the Brazilian government agency

\section{Financial Disclosure and Conflicts of Interest}

The authors declare that there are no conflicts of interest to disclose.

\section{Author Contribution}

E.D.B.P., C.B.A.M., L.S.M., and I.C.N. developed the research question and designed the study. E.D.B.P., P.F.C.B. conducted the statistical analyses. J.H.P.G., C.F.G.V., P.F.C.B., E.F.D., and E.D.B.P. contributed to the draft of the manuscript. All authors read and approved the final manuscript.

References

1 Feltracco P, Carollo C, Barbieri S, Pettenuzzo T, Ori C: Post-liver transplant pulmonary complications. World J Gastroenterol 2013; 19:9271-9281.

2 Pirat A, Ozgur S, Torgay A, Candan S, Zeyneloğlu P, Arslan G: Risk factors for postoperative respiratory complications in adult liver transplant recipients. Transplant Proc 2004;36:218-220

3 Lin YH, Cai ZS, Jiang Y, Lü LZ, Zhang XJ, Cai QC: Perioperative risk factors for pulmonary complications after liver transplantation. J Int Med Res 2010;38:1845-1855.

4 Huang CT, Lin HC, Chang SC, Lee WC: Preoperative risk factors predict post-operative respiratory failure after liver transplantation. PLoS One 2011;6:e22689. 
5 Levesque E, Hoti E, Azoulay D, Honore I, Guignard B, Vibert E, Ichai P, Antoun F, Saliba F, Samuel D: Pulmonary complications after elective liver transplantation - incidence, risk factors, and outcome. Transplantation 2012;94:532-538.

6 Mancuzo E, Pereira R, Sanches M, Mancuzo A: Pre-transplant aerobic capacity and prolonged hospitalization after liver transplantation. GE Port J Gastroenterol 2015;22:83-84.

7 Bernal W, Martin-Mateos R, Lipcsey M, Tallis C, Woodsford K, McPhail MJ, Willars C, Auzinger G, Sizer E, Heneghan M, Cottam S, Heaton N, Wendon J: Aerobic capacity cardiopulmonary exercise testing and survival without liver transplantation for patients with chronic liver disease. Liver Transplant 2014; 20:54-62.

8 Alameri HF, Sanai FM, Al Dukhayil M, Azzam NA, Al-Swat KA, Hersi AS, Abdo AA: Six min walk test to assess functional capacity in chronic liver disease patients. World J Gastroenterol 2007;13:3996-4001.

9 Carey EJ, Steidley DE, Aqel BA, Byrne TJ, Mekeel KL, Rakela J, Vargas HE, Douglas DD: Six-min walk distance predicts mortality in liver transplant candidates. Liver Transplant 2010;16:1373-1378.

10 Pessoa BV, Arcuri JF, Labadessa IG, Costa JNF, Sentanin AC, Di Lorenzo VAP: 2 Validity of the six-min step test of free cadence in patients with chronic obstructive pulmonary disease. Braz J Phys Ther 2014;18:228-236.

11 Dal Corso S, Duarte SR, Neder JA, Malaguti C, Fuccio MB, Castro Pereira CA, Nery LE: A step test to assess exercise-related oxygen desaturation in interstitial lung disease. Eur Respir J 2007;29:330-336.

12 Paisani DM, Fiore JF Jr, Lunardi AC, Colluci DB, Santoro IL, Carvalho CR, Chiavegato LD, Faresin SM: Preoperative 6-min walking distance does not predict pulmonary complications in upper abdominal surgery. Respirology 2012;17:1013-1017.

13 Lee L, Schwartzman K, Carli F, Zavorsky GS, Li C, Charlebois P, Stein B, Liberman AS, Fried GM, Feldman LS: The association of the distance walked in 6 min with preoperative peak oxygen consumption and complications 1 month after colorectal resection. Anaesthesia 2013;68:811-816.

14 Keeratichananont W, Thanadetsuntorn C, Keeratichananont S: Value of preoperative 6-minute walk test for predicting postoperative pulmonary complications. Ther Adv Respir Dis 2016;10:18-25

15 Sinclair RCF, Batterham AM, Davies S, Cawthorn L, Danjoux GR: Validity of the $6 \mathrm{~min}$ walk test in prediction of the anaerobic threshold before major non-cardiac surgery. Br J Anaesth 2012;108:30-35.

16 Smith TB, Stonelli C, Purkayastha S, Paraskevas $\mathrm{P}$ : Cardiopulmonary exercise testing as a risk assessment method in non cardiopulmonary surgery: a systematic review. Anaesthesia 2009;64:883-893.
17 Feltracco P, Barbieri S, Galligioni H, Michieletto E, Carollo C, Ori C: Intensive care management of liver transplanted patients. World J Hepatol 2011;27:61-71.

18 De Gasperi A, Feltracco P, Ceravola E, Mazzaa E: Pulmonary complications in patients receiving a solid-organ transplant. Curr Opin Crit Care 2014;20:411-419.

19 Canet J, Gallart L, Gomar C, Paluzie G, Vallés J, Castillo J, Sabaté S, Mazo V, Briones Z, Sanchis J; ARISCAT Group: Prediction of postoperative pulmonary complications in a population-based surgical cohort. Anesthesiology 2010;113:1338-1350.

20 Fernandez-Perez ER, Keegan MT, Brown DR, Hubmayr RD, Gajic O: Intraoperative tidal volume as a risk factor for respiratory failure after pneumonectomy. Anesthesiology 2006; 105:14-18.

21 ATS/ERS Task Force Standardisation of Lung Function Testing: Standardisation of spirometry. Eur Respir J 2005;26:319-338.

22 Green M, Road J, Sieck GC, Similowski T: Tests of respiratory muscle strength. Am J Respir Crit Care Med 2002;166:528-547.

23 American Thoracic Society Statement: 312 guidelines for the six-minute walk test. Am J Respir Crit Care Med 2002;166:111-117.

24 Arcuri JF, Borghi-Silva A, Labadessa IG, Sentanin AC, Candolo C, Pires Di Lorenzo VA: Validity and reliability of the 6-min step test in healthy individuals: a cross-sectional study. Clin J Sport Med 2016;26:69-75.

25 Golfieri R, Giampalma E, Morselli Labate AM, d'Arienzo P, Jovine E, Grazi GL, Mazziotti A, Maffei M, Muzzi C, Tancioni S, Sama C, Cavallari A, Gavelli G: Pulmonary complications of liver transplantation: radiological appearance and statistical evaluation of risk factors in 300 cases. Eur Radiol 2000;10:1169.

26 Levesque E, Hoti E, Jiabin J, Dellamonica J, Ichai P, Saliba F, Azoulay D, Samuel D: Respiratory impact of paracentesis in cirrhotic patients with acute lung injury. J Crit Care 2011; 26:257.

27 McAlister VC, Grant DR, Roy A, Brown WF, Hutton LC,Leasa DJ, Ghent CN, Veitch JE, Wall WJ: Right phrenic nerve injury in orthotopic liver transplantation. Transplantation 1993;55:826-830.

28 Gu XP, Jiang Y, Xu FT, Qiu YD, Ding YT: Effect of cold-ischemia time on nuclear factorkappaB activation and inflammatory response in graft after orthotopic liver transplantation in rats. World J Gastroenterol 2004;10:1000-1004.

29 Totsuka E, Fung JJ, Hakamada K, Ohashi M, Takahashi K, Nakai M, Morohashi S, Morohashi H, Kimura N, Nishimura A, Ishizawa Y, Ono H, Narumi S, Sasaki M: Synergistic effect of cold and warm ischemia time on postoperative graft function and outcome in human liver transplantation. Transplant Proc 2004; 36:1955-1958.
30 Barreto AG, Daher EF, Silva Junior GB, Garcia JH, Magalhães CB, Lima JM, Viana CF, Pereira ED: Risk factors for acute kidney injury and 30-day mortality after liver transplantation. Ann Hepatol 2015;14:688-694.

31 Hofer I, Spivack J, Yaport M, Zerillo J, Reich DL, Wax D, DeMaria S Jr: Association between anesthesiologist experience and mortality after orthotopic liver transplantation. Liver Transpl 2015;21:89-95.

32 da Costa JNF, Arcuri JF, Gonçalves IL, Davi SF, Pessoa BV, Jamami M, Di Lorenzo VAP: Reproducibility of cadence-free 6-minute step test in subjects with COPD. Respir Care 2014;59:538-542.

33 Pichon R, Couturaud F, Mialon P, Le BerMoy C, Péran L, Lochon C, Nowak E, Beaumont $\mathrm{M}$ : Responsiveness and minimally important difference of the 6-min stepper test in patients with chronic obstructive pulmonary disease. Respiration 2016;91:367-373.

34 Müller MJ, Lautz HU, Plogmann B, Burger M, Korber J, Schimidt FW: Energy expenditure and substrate oxidation in patients with cirrhosis: the impact of cause, clinical staging and nutritional state. Hepatology 1992;15: 782-794.

35 Müller MJ, Fenk A, Lautz HU, Selberg O, Canzler H, Balks HJ, von zur Mühlen A, Schmidt E, Schmidt FW: Energy expenditure and substrate metabolism in ethanol-induced liver cirrhosis. Am J Physiol 1991;260:338344.

36 Møller S, Henriksen JH: Cirrhotic cardiomyopathy. J Hepatol 2010;53:179-190.

37 Lemyze M, Dharancy S, Wallaert B: Response to exercise in patients with liver cirrhosis: implications for liver transplantation. Dig Liver Dis 2013;45:362-366

38 Jones JC, Coombes JS, Macdonald GA: Exercise capacity and muscle strength in patients with cirrhosis. Liver Transplant 2012;18:146151.

39 Prentis JM, Manas DM, Trenell MI, Hudson M, Jones DJ, Snowden CP: Submaximal cardiopulmonary exercise testing predicts 90 day survival after liver transplantation. Liver Transplant 2012;18:152-159.

40 Dharancy S, Lemyze M, Boleslawski E, Neviere $R$, Declerck N, Canva V, Wallaert B, Mathurin P, Pruvot FR: Impact of impaired aerobic capacity on liver transplant candidates. Transplantation 2008;86:1077-1083.

41 Tzilas V, Bouros D: The six-minute stepper test: solvitur ambulando. Respiration 2016; 91:469-470.

42 Holland AE, Hill CJ, Rasekaba T, Lee A, Naughton MT, McDonald CF: Updating the minimal important difference for six-minute walk distance in patients with chronic obstructive pulmonary disease. Arch Phys Med Rehabil 2010;91:221-225.

43 Puhan MA, Chandra D, Mosenifar Z, et al: The minimal important difference of exercise tests in severe COPD. Eur Respir J 2011;37: 784-790. 